\title{
Governance on Academic Research Frauds in Universities
}

\author{
He-Xiang ZHAO \\ Institute of Science and Technology, North China Electric Power University, Baoding China, 071000 \\ whitehorseman@163.com
}

Keywords: Academic research administration, Academic frauds, Governance countermeasures.

\begin{abstract}
Currently, the types of the academic research frauds by students and teachers in universities are various and rampant, seriously eroding our country's scientific and technological innovation, which brings serious negative impact to science and education, damaging academic image of teachers and students in universities. There are subjective and objective reasons for academic research frauds by students and teachers in universities, involving in lots of contributory elements such as the academic researchers, competent agencies, policies, mechanisms and so on. The containment of academic frauds atmosphere is bound to be a systematic project, and four kinds of forces to deal with academic frauds are to be relied on the morality, the administration, the law and the media.
\end{abstract}

\section{Introduction}

Colleges and universities are an important place and source of scientific and technological innovation. As an important part of the national science and technology innovation system, the universities shoulder heavy historical responsibilities in the original study, research and development and industrialization of scientific and technological achievements. Academic researches refer to all activities of teachers and students in universities are engaged in scientific researches, including basic researches, applied researches and development in natural sciences and social sciences. Since the reform and opening up, the academic researches by universities have witnessed considerable development, however the academic misconducts mainly as scientific frauds as a cancer damaging the healthy body of university researches in our country, hindering the overall development of China's science and technology researches. In recent years, the shocking academic research frauds such as Shanghai Jiaotong University professor Chen Jin's "Chinese core" chips fraud case, Tsinghua University professor Liu Hui's academic fraud case etc. came to light. Therefore, this article studies the academic frauds by university teachers and students in a hope to manage seek countermeasures to deal with the academic misconducts.

\section{Main types of academic frauds and their performances}

Academic research frauds in universities, also known as academic misconducts in universities, refer to bad activities of teachers and students in universities such as frauds or anomie violating integrity and faithfulness manifested in the real scientific spirits and morals while conducting scientific and academic researches, damaging academic image of teachers and students in universities. Academic research frauds in universities are in various types, which might be classified as follows:

\section{Frauds in academic essays}

While in the process of formation or publication of academic essays the teachers and students in universities fabricated or falsified research data in order to achieve their purpose of the arguments or conclusions, or plagiarized as their own by modifying or directly moving the existing academic results into their own essays and books. The detailed performances are as follows: Fabricating, beautifying or exaggerating the data in some papers; one article with many publications; picking-up in signing the papers; plagiarism without citation or notes; papers written by others, etc. 


\section{Frauds in research programs}

The teachers and students in universities often conduct academic researches by relying on some research programs, while there are possibly frauds in the full process of program research from getting approval, to applying for acceptance, results identification, rewards, etc. Some people successfully obtained approval, acceptance, rewards for the programs through bartering or establishing social relations; some brazenly tampering trial data, deceiving or exaggerating research results, fabricating papers through money; some asking the experts to sign for gratitude, for money or power through bartering or establishing social relations.

\section{Frauds in educational backgrounds}

In order to get some jobs, programs, awards, adoption, reputation, etc., many teachers and students in universities may take risks by make frauds in their qualifications, titles, specialties, identities, etc. to muddle through.

\section{Frauds in using research funding}

In the research process the use of certain funds always be involved, some teachers and students in universities might cheat to take research funding by providing false invoices, under false pretenses, or with a rebate commission to make a profit or fill their own pockets and so on. Strictly speaking, frauds in using research funding do not belong to academic misconduct, but belong to financial fraud. However, different from the common economic activities, they own a relationship difficultly separating from scientific researches, this article classifies them into the broad academic frauds.

\section{Analysis on the causes of academic frauds}

Currently, behind the rampant phenomenon of academic frauds in universities are complex and diverse causes, which can be classified into different categories with different standards. Based on closeness with the counterfeiters, these reasons of academic frauds might be classified into subjective reasons and objective reasons. Those directly attributed to own subjective intents of the counterfeiters are called subjective reasons, otherwise as objective reasons.

\section{Subjective reasons}

Firstly, in terms of the motivation of frauds, the teachers and students making academic frauds in academic essays, research programs, academic status and use of funds, etc. may intently obtain or maintain illegitimate interests manifested as money, fame, status and so on. Therefore, eagerness for quick success and instant benefit are false motives of academic frauds. Secondly, lacking academic integrity and faithfulness is the individual moral factors for the counterfeiters forgetting honor at the prospect of profits to take a risk. Thirdly, the leaderships of some universities with strong official standard are very common. In order to prove they can do anything, be good at anything, they constantly look for opportunities to prove themselves only by making academic frauds. Finally, scientific research needs to be honest. Some teachers and students in universities are impatient, among which some emphasize quantity instead of quality, and others make wantonly frauds. Academic impetuosity induces academic frauds, and vice versa.

\section{Objective reasons}

Of course, the rampant phenomenon of academic frauds in universities are closely related to counterfeiters' morality, but more to which there are objective conditions contributing to academic frauds.

\section{Lack of effective oversight mechanisms being the basic cause for the frauds in research programs}

Firstly, the chiefs of research programs put more on program application and less on program implementation, commonly in lack of sense of responsibility, for which after establishment of the programs, the program leaders do not start work in accordance with the plan with greater 
randomness. Secondly, the lack of effective evaluation system and mechanisms for the results of programs, and the excessive administrative intervention seriously affect the effectiveness and quality of the program argumentation. Thirdly, scientific management system and penalties are not perfectly available. When unreasonable delays or failure to achieve research goals, some hastily concluded, and some make frauds without any compulsory treatment. And the administrative system makes space for academic frauds to be made. Finally, problems exist in approving and supervising academic funding. In China, there are so-called "academic research contractors", who by making use of their academic reputations and superb relations with officials possess a large number of scientific and technological resources, and then subcontract them to make more funds through various ways into their own pockets.

\section{Lack of legal standards on plagiarism is a significant cause for paper frauds}

In China, there are no clear and detailed specifications on plagiarism. In some country, it might be viewed as plagiarism if in an article there are six sentences same as the others'. Whereas how the data are cited to prove their own points of view is in no standards, which will easily lead to plagiarisms and other academic misconducts.

\section{Academic environment is not relaxed}

In China, that there is no good academic research environment, especially not allowing to fail, might be the most prominent problem. It is not hard to see or hear news of research failures in the domestic media. In lack of academic environment allowing to fail, and coupled with pursuit of material interests, teachers and researchers make frauds in researches and briberies, and so on. It can be said, to some extent, that it is the academic environment making them abandon rigorous scholarship and go on a wrong way.

\section{The judicial process is not introduced}

At present, the government is too lenient to academic frauds, imposing too much emphasis on ethics and morals instead of introducing judicial proceedings. Once the frauds were exposed, the penalties such as removal from positions, termination of contracts, termination of programs, cancelling titles, recovery of funds and so on seem very heavy. In fact, the raised hand is just gently falling without taking any legal responsibilities. Without introducing judicial process, no matter how perfect the rules and regulations are only on paper with no effect.

\section{Modern computer technology has facilitated academic misconducts}

As the core of modern information technology revolution, computer technology might be a double edged sword. At the same time of enhancing the level of scientific research accurately, fast and objectively, it also provides some scholars convenience to make academic misconducts through data frauds, image synthesis, curve correction and direct download and so on.

\section{Academic frauds are promoted by some journals or publishers that are not strict or seek rents with power}

In practice, many publishing units do not strictly comply with the law, either pay attention to protect the copyrights, which is fueling the spread of academic misconducts. Some journals sell the publishing pages to obtain money, and have the authors to bear responsibilities by themselves, regardless of whether there is a paper or book fraud.

\section{Countermeasures to academic frauds}

\section{To establish a sound full-process scientific research monitoring mechanism}

Started from establishment of programs, the reforms should be deepened upon administrative approval system and technological programs management system, ensuring the whole process of establishment of programs to be open, fair and transparent. A new scientific and technological achievements evaluation mode should be initiated, in which the industry-related outcomes might be 
evaluated by the market, those of basic researches might be recognized through papers, citations, international conferences. An accountability and efficiency system should be developed to make track assessment to the relative responsibility bearers and strengthen the funds monitoring through special audits, and strengthen reviews on authenticity of scientific and technological achievements through peer reviews and public oversights.

\section{To establish a scientific academic evaluation mechanism to ensure academic quality}

Firstly, academic evaluation cannot be linked directly with interests. A scientific academic incentive mechanism should be established to provide the researchers a free, relaxed academic space in order that they will not be tired of salary, promotion, title, awards and they can freely play, concentrate on researches and innovation. Secondly, papers should not be the sole indicator for granting diplomas. The reforms on granting diplomas should be taken into consideration a variety of aspects that might show the academic capabilities. Thirdly, the scientific level of academic evaluation should be improved, changing assessment emphasizing the numbers of results to the quality of outcomes, from the journal level to the content of the results. Lastly, in principle the second author or those nominal authors should not be taken into assessment.

\section{To strengthen construction on academic ethics}

On the one hand, a good atmosphere of academic ethics need be created. Universities should put scientific ethics and integrity education into compulsory college courses, and put the researchers into vocational training system, laying good foundation for promoting the researchers' scientific and moral qualities. The punishment on academic frauds should be carried out by taking faithfulness as pride and frauds as shame, in which the presidents of universities should play a vanguard and encourage exposition of academic misconducts to create a good moral atmosphere for academic research. On the other hand, a sound system of complete academic norms should be established. For example, Such as the universities should build credit files to make fraud as a lifelong stain, affecting his later living everywhere. The relative systems should be set up such as commitment to the integrity of papers, academic ethics regulations for students, papers quality control system, papers review and corresponding avoidance system and penalty system, combining supervision and punishment together.

\section{To perfect relevant laws and introduce judicial proceedings for academic frauds}

The intellectual property protection laws related to academic research in China such as Copyright Law, Patent Law, Criminal Law and so on should be perfected, and through the relevant legal interpretation to define fraud standards such as plagiarism, etc. Judicial punishment to the counterfeiters should be raised to the height of enhance the future national competitiveness, in which it is necessary for the discipline inspection departments and the judiciary to interfere investigation of academic frauds. After the facts were ascertained, the persons concerned should be held responsible legally to collect economic losses and other losses as far as possible. When introducing judicial procedures to deal with the counterfeiters, the leaders who tolerate frauds, provide protection for the counterfeiters, the experts who make false identification conclusions, the approval authorities use their powers to approve false programs, and the periodicals and publishing units should also be held as responsible as the counterfeiters.

\section{Conclusion}

Due to reasons for academic research frauds by students and teachers in universities involving in lots of contributory elements such as the academic researchers, competent agencies, policies, mechanisms and so on, the containment of academic frauds atmosphere is bound to be a systematic project, and four kinds of forces to deal with academic frauds are to be relied on the morality, the administration, the law and the media. However, more researchers and scientific journal editors believe that the most important moral force is moral because academic research should not only to follow truth-seeking ethics but also to follow the requirements of the moral goodness of people, 
seeking goodness to better seek truth. If academics lack of scientific ethics, lack of integrity and self-discipline, so even if other forces bigger, can only be less effective.

\section{References}

[1] Huang Yisheng. On Issues of Domestic Academic Misconducts by Taking Papers Frauds as Example[J]. Journal of South China Normal University(Social Science Edition), 2006(6).

[2] Wang Youqiang. The Reflect on Scientific Fraud[J]. Chinese Journal of Medical Ethics, 2006(2).

[3] Li Menghui. Reflection on Restraining Academic Cheating in Universities[J]. Journal of Yichun University (Social Science), 2007(1).

[4] Yin Hua. Supervision Obstacles in Scientific Research Management in Universities Exampled by Chinese Core Case[J]. Journal of Technology Economy Market, 2006(8).

[5] Liu Jianxiang, Luo Chengyi. Ethics Consideration Based on University Academic Cheating[J]. Journal of University of South China(Social Science Edition), 2010(4).

[6] Qu Mei. On Phenomenon of Instant Success Seen from Academic Frauds [J]. Medicine and Philosophy(Humanistic \& Social Medicine Edition), 2007(7). 